\title{
The Social Exclusion and Sexual Objectification among males, ages 18-30 years old in Kosovo
}

\author{
MsC. Islam Borinca \\ Department of Psychology, \\ University of Prishtina “ Hasan Prishtina”, Prishtine, Kosovo \\ Presented at University of Prishtina, June/20/2015
}

doi: 10.19044/esj.2016.v12n5p140 URL:http://dx.doi.org/10.19044/esj.2016.v12n5p140

\begin{abstract}
This study aims: Higher levels of gender-based rejection sensitivity would be related to higher tendencies to objectify women, i.e., with higher tendencies to perceive women as lacking of human mental states and uniquely human emotions. In turn, verifying whether such enhanced tendency to perceive women as objects would increase men's tendencies to accept the myth rape acceptance. More specifically, a correlation analysis showed that: The rejection sensitivity index did not correlate with any outcome variable; The tendency to objectify women did not correlate with myth rape acceptance; Hurt proneness or anxiety in close relationships was positively correlated with the tendency to perceive women as human beings (rather than objects) and to attribute them human emotions or human mental states. Interestingly, these latter relations clearly emerged among male participants currently involved in romantic relationships; Instead, a onesample $t$-test showed that the levels of myth rape acceptance were moderately high.
\end{abstract}

Keywords: Social Exclusion, Sexual Objectification, Gender-based rejection sensitivity, Kosovo

\section{Introduction}

Gender is an important consideration in development. It is a way of looking at how social norms and power structures impact on the lives and opportunities available to different groups of men and women. Globally, more women than men live in poverty. Women are also less likely than men to receive basic education and to be appointed to a political position nationally and internationally. Understanding that men and women, boys and girls experience poverty differently and face different barriers to accessing services, economic resources, and political opportunities helps to target 
interventions (World Bank, 2012).

In many countries, women's access to justice is obstructed by statutory and customary laws that are biased against women or are not gender-sensitive. Even where there is a formal legal equality, women often face discrimination from state and non-state institutions. Structural inequalities, such as lack of time, access to resources and education, can restrict women's ability to engage adequately with the bodies that implement justice. These concerns need to be addressed in the design of justice interventions to ensure that both women and men's legal rights are realized (UND, 2010).

Related to that, Kosovo's women are discriminated in many aspects, including social exclusions in education, property, and job (KWN, 2008). Furthermore, Kosovo's women face significant gender-based violence and little respect for a victim's right to confidentiality. Even if a woman musters the courage to report a crime of violence and denounces the perpetrator, she continues to be re-victimized during examination by doctors or forensic examiners, social welfare workers or other actors within and outside the criminal-justice system. In Kosovo, because of its predominantly patriarchal society, "male violence against women is generally unchallenged and victims who choose disclosure may be met with isolation or blame (Tracking Gender-Based Human Rights Violations in Postwar Kosovo, 2004).

During the last decades, a vast amount of research (see Gervais, 2013 for a review) revealed that sexual objectification is one of the most powerful means that men use to legitimize their dominance in society and, ultimately to justify aggressive behaviors toward them. Thus, understandings the processes underlying and exacerbating sexual objectification is a compelling task for scholars. To date, the causes of sexual objectification have been mainly explored within social and cultural aspects of everyday life (e.g., parenting, mass media). However, it is possible that sexual objectification may also depend on individual differences. In particular, in the present work, I am investigating whether the men's perceptions of being socially excluded by women in romantic relationships would enhance their tendency to objectify them.

\section{Social Exclusion}

If no one turned round when we entered, answered when we spoke, or minded what we did, but if every person we met "cut us dead," and acted as if we were non-existing things, a kind of rage and impotent despair would ere long well up in us, from which the cruelest bodily tortures would be a relief; for these would make us feel that, however, bad might be our plight, we had not sunk to such a depth as to be unworthy of attention at all. ( James, 1890/1950, pp. 293-94). 
Belonging is a fundamental requirement for security, reproductive success, and mental health (Baumeister \& Leary, 1995; Smith, 1999). The past decade has witnessed a proliferation of research interest on what happens when people are ostracized, socially excluded or rejected (Williams, 2006).

In addition to it, social exclusion describes a situation where certain groups within a society are systematically disadvantaged because they are discriminated against. Such groups are often differentiated by race, ethnicity, age, sexual orientation, religion, caste, or gender (CUE, 2002), also, ostracism may lead to other maladaptive decisions and behaviors precisely because of a need to belong (Baumeister \& Leary, 1995) and to be accepted by others. Ostracism can cause such a strong desire to belong, to be liked by someone, perhaps anyone, that individuals' ability to discriminate good from bad may be impaired to the point that they become attracted to any group that will have them, even cults and extremist groups(Gruter \& Masters, 1986).

So ostracism as a form of social exclusion occurs not only in dyads and small groups, but also at the societal and global level, and it is perhaps even more important to discover how groups who are ostracized within their city, nation, or in the world community respond. Groups might be buffered from some threats (e.g., they can seek each others' support to maintain a sense of belonging), but they might also be predisposed to respond provocatively and hostilely, to gain attention and respect (Hogg, 2005 \& Jetten, 2006).

Kipling Williams (1997, 2001; Williams \& Zadro, 2005) when formulating the first theory related to social exclusion and ostracism proposes the following sequences: (a) reflexive painful response to any form of ostracism, unmitigated by situational or individual difference factors; (b) threats to the need for belonging, self-esteem, control, and meaningful existence, and increases in sadness and anger; and (c) a reflective stage that is responsive to cognitive appraisals of the situation.

Another major theoretical perspective that has gained support focuses primarily on how ostracism, social exclusion, and/or rejection thwart the need to belong, in particular (Gardner,2005; Pickett \& Gardner, 2005), and how a psychological system-the social monitoring system helps regulate optimal levels of belongings. When belonging is threatened, the individual is motivated to attend more carefully to social cues, presumably to achieve success in subsequent social interactions (Williams, 2006).

A third theoretical framework argues that the blow of social exclusion is much like the blow of a blunt instrument, and it causes a temporary state of cognitive deconstruction (Baumeister, 2002) much like the effectively flat stage that precedes suicide attempts. This explanation has been offered, 
especially when socially excluded individuals show no signs of mood impact (see also Baumeister \& DeWall, 2005).

Many studies have examined various self-reported levels of distress following ostracism, social exclusion, and rejection. These measures may include assessments of mood (usually sadness and anger), hurt feelings, levels of belonging, self-esteem, control, and meaningful existence, and more direct measures of distress or pain. Several studies have measured selfesteem, finding reductions following temporary or remembered instances of rejection and ostracism (Leary, 1995; Sommer, 2001; Williams, 2000; Zadro, 2004).

However, no studies so far have examined whether social exclusion would be related to the tendencies to objectify others. To fill this gap, I explored whether men's experiences of social exclusion within gender-based relations would be related to higher tendencies to objectify women.

\section{Objectification}

People can view the same event, person, or thing in multiple ways. Using an example from photography to illustrate this point, people can use a telephoto lens and zoom in on the specific parts of another person or people can adopt a wide angle lens and focus on the entire person. This involves adopting different processing styles when seeing or thinking about stimuli in our environments. A global processing style involves focusing on the Gestalt, whereas a local processing style involves focusing on the constituent parts (Förster \& Dannenberg, 2010).

Scholars across many disciplines have argued that people are sometimes processed, perceived and treated as objects. This process is called objectification and occurs when people are treated as mere instruments instead of persons. Specifically, when a person's body parts or functions separate from the person, reduced to the status of the instruments, or regarded as capable of representing the entire person, he or (most often) she is said to be objectified (Bartky, 1990; Fredrickson and Roberts, 1997; Gruenfeld,2008; MacKinnon, 1987; Nussbaum, 1995, 1999). For example, economists and philosophers have argued that in capitalism, employers objectify their employees, reducing their employees to their work qualities (Marx, 1964). To the employer, the sum of the employees corresponds to their capacity to get the job done. Likewise, in medicine, physicians may objectify a patient, reducing their patients to their symptoms (Barnard, 2001; Foucault, 1989).

Of greatest familiarity and empirical examination, scholars have noted that women are sexually objectified in many contexts resulting in significant consequences (Bartky, 1990; Code,1995; Fredrickson \& Roberts, 1997; LeMoncheck, 1985; McKinley \& Hyde, 1996; Nussbaum, 1999). 
Although the origins of these considerations are in critiques of pornography (Dworkin, 1981; MacKinnon, 1987, 1989, 2006), more recent inquiries represent sexual objectification as a specific type of appearance-focus concentrated on sexual body parts that also emerges from everyday interactions. According to the objectification theory (Fredrickson \& Roberts, 1997), when sexually objectified, a woman's sexual body parts or functions separate from her person for the use of another. Sexual objectification may be represented on a continuum with more blatant acts and violence, such as assault, exploitation, and trafficking falling on one end and more subtle and covert acts, such as objectifying gazes, inappropriate sexual innuendo, and appearance compliments falling at the other end. Representing a form of body reduction (Langton, 2009), sexual objectification emerges when people focus on women's appearances, bodies, sexual body parts, or sexual functions more than their faces and other non-observable attributes, such as thoughts, feelings, and desires (e.g., Loughnane al., 2010; Vaes, 2011, see also Archer, 1983).

Philosophical and feminist definitions of objectification (Kant, 1785/1998; MacKinnon, 1993; Dworkin, 1997; Nussbaum, 1995) converge on the notion that objectification involves stripping a person of their personhood. In the words of Martha Nussbaum, "objectification entails making into a thing, treating as a thing, something that is really not a thing (1995, p. 257)." Instrumentality, where a person is treated as a tool for another's purposes, is the main feature of Kant's, Dworkin's and MacKinnon's definitions. Nussbaum (1995) offers a broader conceptualization, identifying seven features involved in the notion of objectification: in addition to treating a person as a tool (instrumentality), they are treated as if they are lacking in autonomy and self-determination (denial of autonomy), as if they are lacking in agency and activity (inertness), as if they are interchangeable with other objects (fungibility), as if they lack boundary-integrity, such that it is permissible to break them (violability), as if they can be owned (ownership), and as if their feelings and experiences need not be taken into account (denial of subjectivity). These conditions reflect the treatment of "something, not someone" (Dworkin, 1997, p. 141).

Despite its general name, an objectification theory (Fredrickson \& Roberts 1997, see also McKinley \& Hyde, 1996) was developed for the specific purpose of elucidating the adverse psychological consequences for women living in a society in which they are treated as things rather than people. It suggests that one important consequence of sexual objectification is that women learn to be their first surveyors not only do they experience sexual objectification from others, but they also persistently objectify themselves. When women's self-objectify, they internalize an observer's 
perspective of their bodies and regard their appearance as more important to their self-concept than their other attributes (e.g., physical health, emotions, cognitions; Bartky, 1990; Berger, 1972; de Beauvoir, 1952; Fredrickson \& Roberts, 1997; McKinley, 1998, 2006; McKinley \& Hyde,1996).

Through sexual objectification experiences in the media and interpersonal interactions, girls and women learn that it is adaptive to focus on their appearance more than their other attributes. For example, previous research has shown that women (vs. men) consider their observable physical appearance attributes (e.g., body measurements) as more central to their selfconcept compared to less observable physical competence characteristics (e.g., strength; Noll \& Fredrickson, 1998) and persistently think about how they look (McKinley \& Hyde, 1996).

A multitude of negative consequences is posited to result from objectification experiences through the self-objectification process, including appearance anxiety, body surveillance, body shame, and a diminished capacity for peak motivational states. These intermediary consequences set the stage for psychological disorders that disproportionately affect women; including unipolar depression, eating disorders, and sexual dysfunction (see Calogero,2011; Moradi \& Huang, 2008).

\section{The Present Research}

This project centers around the antecedents of women objectification, i.e., the perception of women as mere objects rather than persons, as tools aimed at satisfying the male sexual desires. To date, psychosocial studies on the antecedents of sexual objectification have mainly focused on social and cultural aspects (e.g., parenting, mass media) that permeate a given society. However, it is plausible to imagine that the sexual objectification stems from an interaction between social factors and individual differences. This latter aspect has been neglected from the literature on sexual objectification so far (Bartky, 1990; Fredrickson \& Roberts, 1997; Gruenfeld, 2008; MacKinnon, 1987; Nussbaum, 1995, 1999; Greivas, 2013).

To fill this gap, we aim at analyzing the gender-based social exclusion (or the gender-based fear of being rejected) as an individual antecedent of sexual objectification. In particular, we hypothesize that for men's experiences of social exclusion in romantic relations would increase their tendency to objectify women. Such relation could be explained, on the one hand, by the greater need of men who perceive of being socially excluded or rejected in gender-based relations to control and to dominate the woman and the relation with her. More clearly, perceiving the woman as an object, rather than as a person, would facilitate the perception of control of the interaction with her. On the other hand, objectifying women would serve as a self-protective mechanism that would allow men's with higher levels of 
perceptions of gender-based social exclusion to cope with an expected exclusion from women (Bastian \& Haslam, 2010).

\section{Hypothesis}

H1. Higher levels of gender-based rejection sensitivity would be related to higher tendencies to objectify women, i.e., with higher tendencies to perceive women as lacking of human mental states and uniquely human emotions. In turn, verifying whether such enhanced tendency to perceive women as objects would increase men's tendencies to accept the myth rape acceptance.

H2. Hurt proneness in gender-relations and an anxious attachment style in romantic relationships would predict higher tendencies to objectify women and, presumably, higher levels of myth rape acceptance.

\section{Method}

\section{Participants}

The initial sample consisted of 98 male participants. All participants were Kosovo citizens. After the first inspection of their socio-demographic information, the data of four participants were not considered in the analyzed because they did not express their sexual orientation, whereas the remaining participants declared being heterosexual. This left a sample of 94 participants. The participants' age ranged from 18 to 30 years (Mage = 24.27; SD = 3.56). At the moment of the survey, 54 participants had a romantic relationship.

\section{Procedure}

Participants were recruited conveniently in a voluntary manner. The study was presented as an investigation concerning people's attitudes and perceptions about gender relations. Questionnaires are provided by Professor Luca Andrihgetto from the University of Genova. In collaborating with a Kosovar bilingual native person prepared the questionnaire in Albanian, by adapting the English version to the Kosovar context. The respondents were instructed as follows: "In the following pages, you will be asked to express your opinions and attitudes by using some response scales whose meaning will be explained later. Further, in the first pages of the survey, you will be asked to remind an event or situation regarding your life and to report it in a written form. Finally, at the end of the questionnaire, you will be asked to provide some demographic information's (e.g., age, sex). The participation in this study is completely voluntary. You are free to decline to participate, to end participation at any time for any reason, or to refuse to answer any individual question”. Also, participants had to sign the agreement participation. Time to fulfill the questionnaires was about 20 minutes. 


\section{The Measures}

We administered a questionnaire (see the Appendix) containing scales adapted from previous works and validated by international literature. In particular, we adapted to the purposes of our research the following scales:

\section{Predictor variables}

Gender-based rejection sensitivity. The gender-based rejection sensitivity was assessed by adapting the scale by Downey \& Feldman (1996). This scale assessed individual differences in the level of concern or anxiety hat men have about being rejected by women in romantic relationships. The measure consisted of 8 hypothetical scenarios. An example follows: "Imagine asking a girl that you have just known to go out with you”. After each scenario, participants were asked to what extent they were concerned about being rejected $(1=$ very unconcerned; $7=$ very concerned) by the woman (e.g., How concerned or anxious would you be over whether or not this girl would go out with you?) and to what extent they expected ( 1 = very unlikely; 7 = very likely) that the woman would accept their invitation or request (e.g., I would expect that she would want to go out with me). Afterward, we calculated a score of rejection sensitivity for each situation by multiplying the level of rejection concern (the response to the first question) by the reverse of the level of acceptance expectancy (the response to question b.). Finally, we computed a rejection sensitivity index by collapsing the eight different scores.

Hurt proneness scale. To measure the participants' proneness to be hurt by women we adapted the Hurt proneness scale (Lear \& Sprienger, 2001). In particular, participants were asked to what extent six sentences described them ( $1=$ it does not describe me at all; $7=$ it describes me at all). Example items were: "My feelings are hurt easily by women"; "Being teased by women hurt my feelings". The six items together did not show a satisfactory reliability, thus, we decided to consider a short version of the scale which considered only the three items that showed a reliable internal consistency $(\alpha=.68)$.

Attachment style in romantic relationships. To measure how participants' live and feel the meaningful relationships in general, respectively if they are anxious or avoidant in romantic relations, we adapted the Attachment style in romantic relationships scale (Clark \& Shaver, 2008) In particular, participants were asked to what extent twelve sentences described them ( $1=$ strongly disagree; $7=$ strongly agree $)$. Example items were: "It helps to turn to my romantic partner in times of need "."I need a lot of reassurance that I am loved by my partner”. The twelve items together did not show a satisfactory reliability, thus, we decided to consider a short version of the scale which consisted of only the four items 
that showed a reliable internal consistency $(\alpha=.57)$.

\section{Outcome variables}

The Mental States Attribution task. The first measure of sexual objectification was the Mental state attribution Task (Haslam, Kashima, Loughna, Shi \& Suitner, 2008).. This task measured participants’ attribution of mental states to women In particular, participants were asked to what extent ( $1=$ not at all; $7=$ very much) women possess 19 different mental states $(\alpha=.75)$., from basic ones (e.g., hearing, seeing) to more complex ones (e.g., needing, planning).

Human emotions task. The second measure of sexual objectification concerned the attributions of emotions, both non-uniquely and uniquely human (see, e.g., Leyens et al., 2000, 2001).In particular, participants were asked to what extent women are able to feel the following emotions from thirteen items $(1=$ not at all; $7=$ very much). Example items were: " Attraction". "Agitation". "Fear".We decided to consider just twelve emotions for this scale, that showed a reliable internal consistency $(\alpha=.69)$.

Myth acceptance scale. To measure the participants' myth rape acceptance about women we adapted the Myth rape acceptance scale (Payne, Lonsway, \& Fitzgerald, 1999). In particular, participants were asked to what extent they agreed or not with nine sentences $(1=$ strongly disagree; $7=$ strongly agree). Example items were: "If a woman is raped while she is drunk, she is at least somewhat responsible for letting things get out of control"."If a woman is willing to "make out" with a guy, then it's no big deal if he goes a little further and has sex". The nine items together showed a reliable internal consistency $(\alpha=.58)$.

\section{Results}

\section{Descriptive Statistics}

As shown in Table 1, with regard the predictor variables, participants showed low proneness to be hurt by women, $\mathrm{M}=3.02, \mathrm{SD}=1.34$, difference from the midpoint (4): $\mathrm{t}(93)=-7.04, \mathrm{p}<.001$. Instead, they displayed moderately high levels of anxiety in close relationships, $\mathrm{M}=4.89, \mathrm{SD}=1.32$, different from the mind-point (4): $t(93)=2.06, p<.041$. With regard the outcome variables, results showed that participant's attributed high capacity for women to feel human mental states, $M=4.91, \mathrm{SD}=.70$, difference from mind-point (4): $\mathrm{t}(93)=12.4, \mathrm{p}<.001$ and to feel human emotions, $\mathrm{M}=5.35$, $\mathrm{SD}=.74$, difference from mind-point(4): $\mathrm{t}(93)=17.77, \mathrm{p}<.001$. Instead, the levels of acceptance toward the rape myth were surprisingly high, $M=4.22$, $\mathrm{SD}=.98$, different from the mind-point (4): at $(93)=2.18, \mathrm{p}<.031$. 
Table 1: Means and standard deviations (in parentheses) for each composite variable

\begin{tabular}{|c|c|c|}
\hline \multicolumn{2}{|c|}{ Variables } & Mean (SD) \\
\hline Rejection sensitivity index & & $81.00(3.52)$ \\
\hline Hurt proneness & & $3.02^{* * *}(1.34)$ \\
\hline Anxiety in romantic relationships & & $4.89 *(1.32)$ \\
\hline Mental State Attribution Task & & $4.91^{* * *}(0.70)$ \\
\hline Human emotions & & $5.35^{* * *}(0.74)$ \\
\hline Myth rape acceptance & & $4.22^{*}(0.98)$ \\
\hline
\end{tabular}

Note. Asterisks indicate significant differences from the midpoint of the scale. ${ }^{*} \mathrm{p}<.05 ;{ }^{* * *} \mathrm{p}$ $<.001$

\section{Relation between variables}

As shown in Table 2, rejection sensitivity index does not correlate with any outcome variable. Instead, both the hurt proneness $(\mathrm{r}=.19, \mathrm{p}=.06$, marginal significance) scale and the anxiety $(\mathrm{r}=.32, \mathrm{p}=.01)$ positively correlate with an inclination to attribute women greater capacity to feel human emotions. Further, higher levels of anxiety in close relationships were positively correlated with higher attributions of human mental states to women $(\mathrm{r}=.27, \mathrm{p}=.02)$.

Table 2. Correlations between the composite variables.

\begin{tabular}{c|c|c|c|c|c|c}
\hline Variables & 1 & 2 & 3 & 4 & 5 & 6 \\
\hline 1. Rejection sensitivity index & - & & & & & \\
\hline 2. Hurt proneness scale & $.31^{* *}$ & - & & & & \\
\hline 3. Anxiety in romantic & $.19^{*}$ & $.25^{*}$ & - & & & \\
\hline 4. Mental State Attribution Task & .04 & .17 & $.27^{* *}$ & - & & \\
\hline 5. Human emotions & .14 & $.19^{*}$ & $.32^{* *}$ & $.40^{* * *}$ & - & \\
\hline 6. Myth rape acceptance & .10 & .10 & .19 & .10 & .15 & - \\
\hline
\end{tabular}

Note.Asterisks indicate significant correlations between variables. ${ }^{*} \mathrm{p}<.05{ }^{* *} \mathrm{p}<.01^{* * *} \mathrm{p}<$ .001

By splitting the sample into participants who have a romantic relationship (see Table 3) and participants who have not a romantic relationship (see Table 4) we can observe interesting differences: positive relations between hurt proneness or anxiety in close relationships with MAT or human emotions emerge only for participants who are engaged in romantic relationships. Instead, for participants who were not engaged in romantic relationships, such relations were not significant. Furthermore, participants without relationship show the positive interaction between 
anxiety index and rape myth acceptance. Such positive relation does not emerge among participants engaged in romantic relationships.

Table 3. Correlations between the composite variables. Participants who have a romantic relationship $(N=54)$

\begin{tabular}{l|l|l|l|l|l|l}
\hline Variables & 1 & 2 & 3 & 4 & 5 & 6 \\
\hline 1. Rejection sensitivity index & - & & & & & \\
\hline 2. Hurt proneness scale & $.41^{* *}$ & - & & & & \\
\hline 3. Anxiety in romantic & $.26^{*}$ & $.37^{* *}$ & - & & & \\
\hline 4. Mental State Attribution Task & -.02 & $.28^{*}$ & $.35^{* *}$ & - & & \\
\hline 5. Human emotions & .18 & $.32^{*}$ & $.41^{* *}$ & $.42^{* * *}$ & - & \\
\hline 6. Myth rape acceptance & .03 & -.01 & .11 & .10 & .15 & - \\
\hline
\end{tabular}
.001

Table 4. Correlations between the composite variables. Participants who have not a romantic relationship $(N=40)$

\begin{tabular}{l|l|l|l|l|l|l}
\hline Variables & 1 & 2 & 3 & 4 & 5 & 6 \\
\hline 1. Rejection sensitivity index & - & & & & & \\
\hline 2. Hurt proneness scale & .21 & - & & & & \\
\hline 3. Anxiety in romantic & .12 & .10 & - & & & \\
\hline 4. Mental State Attribution Task & .12 & -.02 & .16 & - & & \\
\hline 5. Human emotions & .09 & -.06 & .16 & $.39^{*}$ & - & \\
\hline 6. Myth rape acceptance & .18 & .23 & $.31^{* *}$ & .14 & .11 & - \\
\hline
\end{tabular}

Note. Asterisks indicate significant correlations between variables. ${ }^{*} \mathrm{p}<.05{ }^{* * *} \mathrm{p}<.01^{* * *} \mathrm{p}<$ .001

More specifically, a correlation analysis showed that:

a) The rejection sensitivity index did not correlate with any outcome variable; b) The tendency to objectify women did not correlate with myth rape acceptance; c) Hurt proneness or anxiety in close relationships was positively correlated with the tendency to perceive women as human beings (rather than objects) and to attribute them human emotions or human mental states. Interestingly, these latter relations clearly emerged among male participants currently involved in romantic relationships; Instead, a onesample t-test showed that the levels of myth rape acceptance were moderately high.

\section{Discussion}

The obtained findings show a different pattern than our hypotheses. Basically, we hypothesized that higher levels of rejection sensitivity or higher levels of fear of being hurt, higher levels of anxiety would lead men to objectify women, i.e., to perceive them as lacking human emotions or mental states. Instead, the findings (partially) show an opposite tendency: 
higher the level of hurt proneness or anxiety in close relationships higher was the tendency to perceive women as human beings and to attribute them human emotions or human mental states. Instead, rejection sensitivity index does not correlate with any outcome variable. However, I believe these are anyway interesting tendencies that would necessitate of a deeper investigation. Indeed, it is plausible to imagine that men with higher heart proneness or with high anxiety in close relationships sensitive give more importance to romantic and "true" relations with women. So, they pay more attention to women's emotions and their states of mind. This could be translated into to higher tendency to attribute mental states or emotions to women (YMI, 2012).

By splitting participants of romantic relationships (yes vs. no) results showed that these positive correlations between hurt proneness or anxiety in close relationships with MAT or human emotions emerge only for participants who were engaged in romantic relationships. Instead, for participants who were not engaged in romantic relationships, such relations were not significant. However, I believe that among men involved in a romantic relationship this significant relation between hurt proneness, anxiety, and mental states or human emotions could happen because of male desire to be very committed and without mistakes during their relationships with their partners, so this makes them see women like human being with feelings and multiple demands. Indeed, if they want to feel safe and be loved by the partner in a relationship, this mean they see their partners like human beings that show to them an attraction, needs, desire, announcer and safety (Critical Half, 2007). Furthermore, participants without relationship show the positive interaction between anxiety index and rape myth acceptance. Unlike participants in the relationship which show the insignificant interaction between these two indexes. These positive correlations between these two indexes are interesting tendencies that would necessitate of a deeper investigation. Indeed, it is plausible to imagine that, this could happen because of the cultural context and experience. Because of cultural context, women always should care how they behave and wearing, so if they try to be open minded and if they don't show the code of wearing, the tendency is to be prejudiced against people. Because of experience context, in Kosovo is a tendency to prejudice and rumored women if they break up a relationship or if they don't accept to be in a relationship (YMI, 2012).I believe that our study advances the existing literature on social exclusion and fear of being rejected.

Until now gender-based rejection sensitivity or hurt proneness has been studying among females and, for instance, London and colleagues (2011) have found that in working settings women who expected and were concerned about rejection based on their gender showed an increased of 
threat-fueled responses. As a consequence, women high in rejection sensitivity detected gender-based rejection more often, consistent with cuetriggered hyper -vigilance for threat. Thus, they engaged in self-silencing and avoidance of discretionary evaluative opportunities, consistent with wanting to prevent rejection from powerful members of the institution on whose approval they depended on. Also, the perception of gender-based rejection in negative experiences and the use of self-silencing led women to feel more alienated and less motivated. Instead, our findings seem to indicate that for men higher levels of hurt proneness or anxiety in romantic relationships may have positive consequences in gender relations, by increasing the attributions of human emotions and mental states in women. These results could be in line with a recent study by Lemay et al. (2012) that show the positive consequences of hurt feelings, hurt facilitates repair of needed relationships. Specifically, hurt individuals want to restore the perpetrator's valuing, feel dependent on the perpetrator's intentions, and feel hurt especially when they need and desire the relationship. Thus, hurt does not motivate destructive responses. Furthermore, hurt signals to perpetrators that victims care about the relationship and elicits perpetrators 'constructive responses, which have benefits that appear to offset hurt feelings, including increasing care and trust. The repair function of hurt appears truly interpersonal-it can be seen not only in the appraisals, goals, and behaviors of hurt victims, but also in the thoughts, feelings, and behaviors of perpetrators.

\section{Limitations and Recommendations}

Despite the interesting findings, the present study has some limitations that could guide further research. First, it's a correlational study that would need to be replicated with an experimental design in which, for example, the gender-based social exclusion is manipulated. In particular, it would be interesting to verify whether the salience of gender-based social exclusion would predict even higher levels of myth rape acceptance.

Second, it would be interesting to replicate the study with other measures of sexual objectification and to replicate the study in other cultural contexts.

\section{Recommendations}

More studies should be made by an expert on this issue, mainly studies which would have institutional support and which will be published with their recommendations.

\section{References:}

Archer, D., Iritani, B., Kimes, D. D., \& Barrios, M. (1983). Face-ism: Five studies of sex difference in facial prominence. Journal of Personality and 
Social Psychology, 45, 725-735.doi:10.1037/0022-3514.45.4.725.

Barnard, A. (2001). On the relationship between technique and dehumanization. In R. C. Locsin (Ed.), Advancing technology caring, and nursing (pp. 96-105). Westport, CT: Auburn House

Bartky, S. L. (1990). Femininity and domination: Studies in the phenomenology of oppression. New York: Routledge.

Bastian, B., \& Haslam, N. (2010).Excluded from humanity: Ostracism and dehumanization.Journal of Experimental Social Psychology, 46, 107-113.

Baumeister RF, Leary MR. (1995). The need to belong: desire for interpersonal attachments asa fundamental human motivation. Psychol. Bull. 117:497-529

Baumeister RF, Twenge JM, Nuss CK. (2002). Effects of social exclusion on cognitiveprocesses: anticipated aloneness reduces intelligent thought. $J$. Personal. Soc. Psychol.83:817-27.

BaumeisterRF,DeWall CN. (2005). The inner dimension of social exclusion: intelligent thoughtand self-regulation among rejected persons. SeeWilliams et al. 2005, pp. 53-75

Berger, J. (1972). Ways of seeing. London: Penguin.

Bonita, L., Geraldine,D., Romero-Canyas, R .,\& Aneeta, R., Diana,T. (2012).Gender-based rejection sensitivity and academic self-silencing in women.Journal of Personality and Social Psychology, Vol 102(5), 961-979 http://dx.doi.org/10.1037/a0026615

Brennan, K. A., Clark, C. L., \& Shaver, P. R. (1998). Self-report measurement of adult romantic attachment: An integrative overview. In J. A. Simpson \& W. S. Rholes (Eds.), Attachment theory and close relationships (pp. 46-76). New York: Guilford Press.

Calogero, R., Tantleff-Dunn, S., \& Thompson, K. (2011). Operationalizing self-objectification:Assessment and related methodological issues. In R. Calogero, S. Tantleff-Dunn, \& J. K.Thompson (Eds.), Self-objectification in women: Causes, consequences, and counteractions(pp. 23-49). Washington, D.C.: American Psychological Association

Code, L. (1995).Rhetorical spaces: Essays on gendered locations. New York: Routledge.

Council of the European Union (2002) 'Fight against poverty and social exclusion: common objectives for thesecond round of the National Action Plans - endorsement' 1416/1/02 REV 1 (SOC 508), Brussels, November

Critical Half. (2007). Special issue: Engaging Men in "Women's Issues": Inclusive approaches to gender and development. Vol. 5 No. 1, Winter. de Beauvoir, S. (1952). The second sex (Trans: Parshley H.M.). New York: Knopf.

Downey, G., \& Feldman, S. I. (1996).Implications of rejection sensitivity for intimate relationships. Journal of Personality and Social Psychology, 70, 
1327-1343.

Dworkin, A. (1997). Intercourse. New York: Free Press Paperbacks

Dworkin, A. (1981). Pornography: Men possessing women. New York: Perigee.

Fredrickson, B. L., \& Roberts, T. A. (1997). Objectification theory: Toward understanding women's lived experiences and mental health risks. Psychology of Women Quarterly, 21, 173-206. doi:10.1111/j.14716402.1997.tb00108.x.

Förster, J., \& Dannenberg, L. (2010).GLOMOsys: A systems account of global versus local processing.Psychological Inquiry, 21, 175-197. doi:10.1080/1047840X.2010.487849.

Foucault, M. (1989).The birth of the clinic. London: Routledge.

Gardner WL, Pickett CL, Knowles M. (2005). Social snacking and shielding: using social symbols,selves, and surrogates in the service of belonging needs. See Williams et al. 2005,pp. 227-42.

Gervais, S. J. (Ed.). (2013). Objectification and (De)Humanization. New York, NY: Springer.

Gruenfeld, D. H., Inesi, M. E., Magee, J. C., \&Galinsky, A. D. (2008). Power and the objectification of social targets.Journal of Personality and Social Psychology, 95, 111-127.doi:10.1037/0022-3514.95.1.111.

Gruter M, Masters RD. (1986). Ostracism: a social and biological phenomenon. Ethol.Sociobiol.7:149-395.

Haslam, N., Bain, P., Loughnan, S., \& Kashima, Y. (2008). Attributing and denying humanness to others.European Review of Social Psychology, 19, 5585. doi:10.1080/10463280801981645.

Haslam, N., Kashima, Y., Loughnan, S., Shi, J., \&Suitner, C. (2008). Subhuman, inhuman, and superhuman: Contrasting humans with nonhumans in three cultures. Social Cognition, 26(2), 248-258. doi:10.1521/soco.2008.26.2.248.

Hogg MA. (2005). All animals are equal but some animals are more equal than others: socialidentity and marginal membership. SeeWilliams et al. 2005, pp. 243-61

James W. (1890/1950). Principles of Psychology, Volume 1. New York: Dover

Jetten J, Branscombe NR, Spears R. (2006). Living on the edge: dynamics of intragroup and intergroup rejection experiences. In Social Identities: Motivational, Emotional and Cultural Influences, ed. R Brown, D Capozza. London: Sage. In press

Kant, I. (1998). Groundwork of the metaphysics of morals (Series: Cambridge Texts in theHistory of Philosophy). M. Gregor (Ed.), Cambridge: Cambridge University Press (Originalwork published 1785).

Kosova Women's Network (KWN). (2008). By Nicole 
Farnsworth.Exploratory Research on the Extentof Gender-Based Violence in Kosova and Its Impact on Women's Reproductive Health.Prishtina, Kosova: KWN.

Langton, R. (2009). Sexual solipsism: Philosophical essays on pornography and objectification.Oxford: Oxford University Press.

Leary MR, Tambor ES, Terdal SK, Downs DL. (1995). Self-esteem as an interpersonal monitor:the sociometer hypothesis. J. Personal. Soc. Psychol. 68:518-30.

Leary, M. R., \& Springer, C. (2001). Hurt feelings: The neglected emotion. In R. M. Kowalski (Ed.), Behaving badly: Aversive behaviors in interpersonal relationships (pp. 151-175). Washington, DC: American Psychological Association

Lemay, E. P., Jr., Overall, N. C., \& Clark, M. S. (2012). Experiences and interpersonal consequences of hurt feelings and anger.Journal of Personality and Social Psychology, 103, 982-1006.

LeMoncheck, L. (1985). Dehumanizing women: Treating persons as sex objects. Totowa, NJ:Rowman and Allanheld Publishers.

Leyens, J-Ph., Rodríguez-Pérez, A.,Rodríguez-Torres, R., Gaunt, R., Paladino, P. M.,\& Vaes, J. (2001). Psychological essentialism andthe differential attribution of uniquely humanemotions to ingroups and outgroups. EuropeanJournal of Social Psychology, 31, 395-411.

Leyens, J.-Ph., Demoulin, S., Vaes, J., Gaunt, R., \&Paladino, M. P. (2007). Infra-humanization: The wall of group differences.Journal of Social Issues and Policy Review, 1, 139-172.

Loughnan, S., Haslam, N., Murnane, T., Vaes, J., Reynolds, C., \&Suitner, C. (2010). Objectification leads to depersonalization: The denial of mind and moral concern to objectifiedothers. European Journal of Social Psychology, 40, 709-717. doi:10.1002/ejsp.755.

MacKinnon, C. (1987). Feminism unmodified: Discourse on life and law. Cambridge, MA:Harvard University Press.

MacKinnon, C. (1989). Toward a feminist theory of the state. Cambridge, MA: HarvardUniversity Press.

MacKinnon, C. (1993). Only words. Cambridge: Harvard University Press.

MacKinnon, C. (2006). Are women human?. Cambridge, MA: Harvard University Press.

Marx, K. (1964). Early writings (Trans: Bottomore, T.B.). New York: McGraw-Hill (Originalwork published 1844).

McKinley, N. M., \& Hyde, J. S. (1996). The objectified body consciousness scale:Development and validation. Psychology of Women Quarterly, 20, 181-215.doi:10.1111/j.1471-6402.1996.tb00467.x.

Moradi, B., \& Huang, Y. P. (2008). Objectification theory and psychology of women: A decadeof advances and futures directions. Psychology of Women 
Quarterly, 32, 377-398.doi:10.1111/j.1471-6402.2008.00452.x.

Nussbaum, M. (1995).Objectification.Philosophy and Public Affairs, 24(4), 249-291.

Nussbaum, M. C. (1999). Sex and social justice.In M. C. Nussbaum (Ed.), Objectification (pp.213-239). New York: Oxford University Press.

Noll, S. M., \& Fredrickson, B. L. (1998).A mediational model linking selfobjectification,body shame, and disordered eating.Psychology of Women Quarterly, 22, 623-636.doi:10.1111/j.1471-6402.1998.tb00181.x.

Payne, D. L., Lonsway, K. A., \& Fitzgerald, L. F. (1999). Rape myth acceptance: Exploration of its structure and its measurement using the Illinois rape myth acceptance scale. Journalof Research in Personality, 33, 27-68.

Pickett CL, Gardner WL. (2005). The social monitoring system: enhanced sensitivity tosocial clues as an adaptive response to social exclusion. See Williams et al. 2005,pp. 213-26

SommerKL,Williams KD, Ciarocco NJ, Baumeister RF. (2001b). When silence speaks louderthan words: explorations into the interpersonal and intrapsychic consequences of socialostracism.Basic Appl. Soc. Psychol. 83:606-15

Smith ER, Murphy J, Coats S. (1999). Attachment to groups: theory and measurement.J. Personal. Soc. Psychol. 77:94-110.

Tracking Gender-Based Human Rights Violations in Postwar Kosovo.(2004). American Journal of Public Health, vol. 94.

United Nations Development Programme (UNDP). (2010). 'Gender, Climate Change andCommunity-Based Adaptation', UNDP, New York

Vaes, J., Paladino, M. P., \&Puvia, E. (2011). Are sexualized females complete human beings?Why males and females dehumanize sexually objectified women. European Journal ofSocial Psychology, 41, 774-785. doi:10.1002/ejsp.824.

Zadro L. (2004). Ostracism: Empirical studies inspired by real-world experiences of silence and exclusion.PhD thesis. Univ.New SouthWales.294 pp.

Williams KD. (1997). Social ostracism.In Aversive Interpersonal Behaviors, ed. RM Kowalski,p. 133-70. New York: Plenum.

Williams KD, Bernieri F, Faulkner S, Grahe J, Gada-Jain N. (2000). The Scarlet LetterStudy: five days of social ostracism. J. Person. Interperson. Loss 5:19-63

Williams KD. (2001). Ostracism: The Power of Silence. New York: Guilford. 282 pp.

Williams KD, Zadro L. (2005). Ostracism: the indiscriminate early detection system. SeeWilliams et al. 2005, pp. 19-34.

Williams, D.K. (2006) Ostracism.Department of Psychological Sciences, 
Purdue University, West Lafayette.

Williams, K. D. (2007). Ostracism.Annual Review of Psychology, 58,425452.

World Bank. (2012). 'Overview' in World Development Report 2012: Gender Equality andDevelopment, World Bank, Washington.http://www.gsdrc.org/go/display\&type=Document\&id=4299 Young Men Initiative, CARE International and Norwegian Ministry of Foreign Affairs (2012),

'The Young Men Initiative - a case study 2012: Engaging young men in the Western Balkans in gender equality and violence prevention' 